\author{
Marquette University \\ e-Publications@Marquette
}

3-3-2008

\title{
Induction Machine Broken Bar and Stator Short-Circuit Fault Diagnostics Based on Three Phase Stator Current Envelopes
}

Aderiano M. da Silva

Rockwell Automation

Richard J. Povinelli

Marquette University, richard.povinelli@marquette.edu

Nabeel Demerdash

Marquette University, nabeel.demerdash@marquette.edu

Follow this and additional works at: https://epublications.marquette.edu/electric_fac

Part of the Computer Engineering Commons, and the Electrical and Computer Engineering Commons

\section{Recommended Citation}

da Silva, Aderiano M.; Povinelli, Richard J.; and Demerdash, Nabeel, "Induction Machine Broken Bar and Stator Short-Circuit Fault Diagnostics Based on Three Phase Stator Current Envelopes" (2008). Electrical and Computer Engineering Faculty Research and Publications. 107.

https://epublications.marquette.edu/electric_fac/107 
Marquette University

e-Publications@Marquette

\section{Electrical and Computer Engineering Faculty Research and Publications/College of Engineering}

This paper is NOT THE PUBLISHED VERSION; but the author's final, peer-reviewed manuscript. The published version may be accessed by following the link in the citation below.

IEEE Transactions on Industrial Electronics, Vol. 55, No. 3 (March 2008): 1310 - 1318. DOI. This article is (C) The Institute of Electrical and Electronics Engineers and permission has been granted for this version to appear in e-Publications@Marquette. The Institute of Electrical and Electronics Engineers does not grant permission for this article to be further copied/distributed or hosted elsewhere without the express permission from The Institute of Electrical and Electronics Engineers.

\section{Induction Machine Broken Bar and Stator Short-Circuit Fault Diagnostics Based on Three-Phase Stator Current Envelopes}

Aderiano M. da Silva

Marquette University, Milwaukee, WI

Rockwell Automation, Mequon, WI

Richard J. Povinelli

Marquette University, Milwaukee, WI

Nabeel A. O. Demerdash

Marquette University, Milwaukee, WI 


\section{Abstract:}

A new method for the fault diagnosis of a broken rotor bar and interturn short circuits in induction machines (IMs) is presented. The method is based on the analysis of the three-phase stator current envelopes of IMs using reconstructed phase space transforms. The signatures of each type of fault are created from the three-phase current envelope of each fault. The resulting fault signatures for the new so-called Idquounseen signalsrdquo are classified using Gaussian mixture models and a Bayesian maximum likelihood classifier. The presented method yields a high degree of accuracy in fault identification as evidenced by the given experimental results, which validate this method.

\section{SECTION I. Introduction}

Induction machines (IMs) are complex electromechanical devices that are utilized in most industrial applications for the conversion of power from electrical to mechanical form. The IMs can be energized from constantfrequency sinusoidal power supplies or from adjustable-speed ac drives. However, IMs are susceptible to many types of fault, especially when supplied by the ac drives. This is due to the extra voltage stresses on the stator windings, the resulting induced bearing currents, and the high-frequency stator current components caused by such drives. In addition, motor overvoltages can occur because of the length of cable connections between a motor and an ac drive. This last effect is caused by the reflected wave transient voltages [1]. For industrial processes, the IM fault monitoring and diagnosis is important to identify motor failures before they become catastrophic and to prevent severe damage to induction motors. Undetected minor motor faults may cascade into motor failure, which in turn may cause production shutdowns. Such shutdowns are costly in terms of lost production time, maintenance costs, and wasted raw materials. According to published surveys, IM failures include bearing failures (which are responsible for $40 \%-50 \%$ of all faults), interturn short circuits in stator windings (which represent $30 \%-40 \%$ of the reported faults), and broken rotor bars and end ring faults (which represent $5 \%-10 \%$ of the IM faults) [2]. This paper is centered on electrically detectable faults that occur in the stator windings and rotor cage, namely interturn stator shorts and broken rotor bars.

Significant efforts have been dedicated to the IM fault diagnosis during the last two decades, and many techniques have been proposed [3]-

[4][5][6][7][8][9][10][11][12][13][14][15][16][17][18][19][20][21][22][23][24]. Several of these fault detection and identification techniques are based on the stator current fast Fourier transform spectral signature analysis, which uses the power spectrum of the stator current [7], [8], [22], [25]. Other techniques include vibration analysis, acoustic noise measurement, torque profile analysis, temperature analysis, and magnetic field analysis [9]-[10][11], [23]. Recently, new techniques based on artificial intelligence (AI) approaches have been introduced using concepts such as fuzzy logic [12]-[13][14], [20], [21], [24], genetic algorithms [11], [15], neural network [16], [17], and Bayesian classifiers [18], [26]. Additionally, a method that uses the motor internal physical condition based on a so-called pendulous oscillation of the rotor magnetic field space vector orientation has been introduced for motor fault classification [5], [19].

This paper presents a method that is based on the analysis of the envelope of the three-phase stator current for broken rotor bars and interturn stator shorts. It was found in this investigation that the three-phase current envelope is a powerful feature for motor fault classification. The envelope signal is extracted from the experimentally acquired stator current signals and is used in conjunction with Al techniques based on Gaussian mixture models (GMMs) and reconstructed phase space (RPSs) to identify motor faults. This method creates signatures for each type of fault based on the three-phase stator current envelope. A signature for each newly acquired input set of three-phase stator currents, which are called "unseen signals," must be generated and compared with all the signatures that represent each type of fault learned from the previously acquired database. The conditional likelihoods between this new signature and the previously learned signatures for each 
type of fault are calculated. Thus, a classifier identifies the previously learned signatures with a maximum likelihood, which now classifies the fault of the so-called "unseen signal" undergoing the process of classification. In this paper, the classification process yielded high accuracy using just a half second of the current signal for a three-phase $460-\mathrm{V} 60-\mathrm{Hz}$ six-pole 5 -hp squirrel-cage induction motor, which is roughly the time equivalent of a third of a slip cycle under normal loads. This will be shown and supported by the experimental results presented in Section III. Again, the presented method is focused on two types of motor faults. Specifically, the first type is the broken rotor bar, and the second one is the interturn short circuit in stator windings.

In addition, the presented method not only classifies an IM as healthy or faulty but also identifies the severity of the fault through the identification of the number of broken rotor bars or the number (or percentage) of shortcircuited turns in the stator windings. This constitutes a powerful means of monitoring motor fault severities, which could possibly predict the time of onset of the complete failure of a motor and thus could help prevent unexpected shutdowns of industrial processes.

The remainder of this paper is organized as follows: Section II details the method, as well as analyzes and discusses the procedure to obtain the current envelope, and discuses the organization of the data sets. Section III presents the experimental results and analysis for broken bars and interturn short circuits in stator windings. This is followed by an overall discussion of results and conclusions.

\section{SECTION II. Background}

This section presents the induction motor fault diagnosis method and explains the procedure to obtain the three-phase stator current envelope signals for broken rotor bars and interturn short-circuit cases. Additionally, a presentation of the approach taken in organizing the data set is given.

\section{A. Methodology}

The fault classification method is based on machine learning techniques [27]. The general concept consists of training the classification algorithm using data sampled from the experimentally acquired three-phase stator currents. These data include different motor operating conditions, including faulty and healthy motor operations. Thus, from each motor operating condition, a signature is generated during the training stage of this method. Additionally, the resulting trained algorithm is tested on the so-called "unseen signals," which constitute the testing set. The accuracy of the motor fault classifier is defined in proportionality to the correctness of the classification of each faulty and healthy case to be identified in the testing set. The training signatures must properly represent the features of each motor operating condition to result in maximum fault diagnosis accuracy.

The process of algorithm training and motor fault classification is based on a previous work detailed in [26], in which one can also find the pseudocode of the approach. In the interest of continuity, essentially, the process consists of constructing a GMM [26] from an RPS [26], [28], [29], where the resulting models are the signatures of the motor operating condition. This RPS-based approach allows for the reconstruction of an IM's state structure [30], [31]. The resulting fault signatures for the "unseen signals" are classified using a Bayesian maximum likelihood classifier [27]. This process has three steps. The first step is data analysis, where the input signals from the training set are normalized to zero mean and then scaled to unit standard deviation. Moreover, two parameters are calculated to construct the RPS, i.e., the time lag and the dimension. The time lag is calculated using the first minimum of the automutual information function, and the dimension is defined using the global false nearest-neighbor technique [26], [28], [29]. The second step is to learn the GMM of the RPS. The time lag and the dimension are used to build the RPS for each class of motor operating conditions. The GMM is learned with $\mathrm{M}$ mixtures for each class of motor operating conditions. The number of mixtures is related to the 
complexity of the models. A higher number of mixtures implies a more complex model. Ideally, a more complex model provides a higher accuracy in signal classification. However, practically, there is an optimal number of mixtures for maximum accuracy, and past that number, the accuracy tends to be lower. Moreover, the parameters of the GMM (centers and covariances) are estimated by an Expectation Maximization algorithm [26], [32]. A GMM of the RPS with dimension of 2, time lag of 9, and eight mixtures is shown in Fig. 1. Moreover, two parameters of the GMM (centers and covariances) are also shown in Fig. 1 . The last step is that of motor fault classification. The signature for an "unseen signal" is classified using the previously trained GMMs. The RPS of the "unseen signal" is constructed with the same dimension and time lag of the previously learned signatures. The Bayesian maximum likelihood classifier [27] computes the conditional likelihood of the signatures for this "unseen signal" under each signature (GMM) previously learned using the training set. The learned signature with maximum likelihood defines the particular class of motor operating condition (faulty or healthy). The algorithm of this overall method is depicted in the functional flow chart of Fig. 2 . In this figure, the results obtained in the training stage (a) are followed by the fault classification stage (b) of the algorithm.

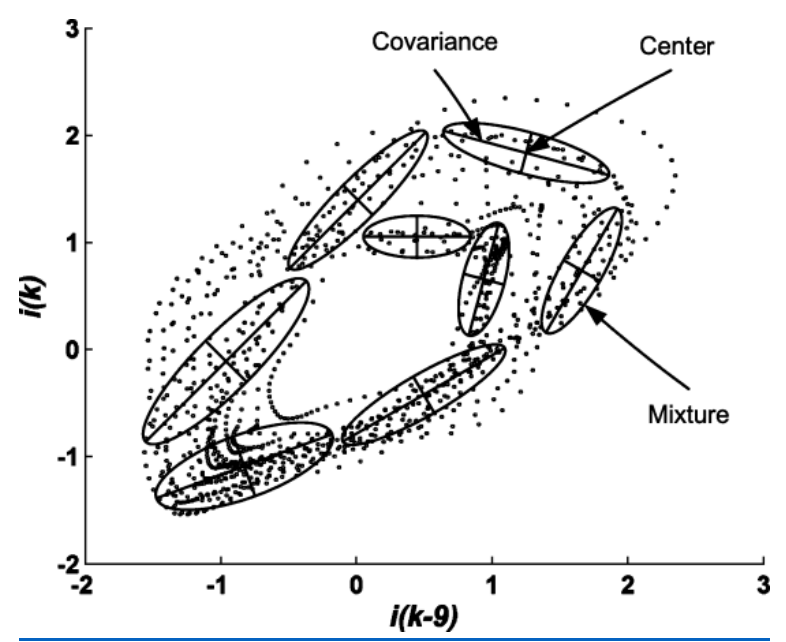

Fig. 1. GMM of the three-phase stator current envelope of a faulty IM RPS with eight mixtures, dimension of 2, and time lag of 9 .

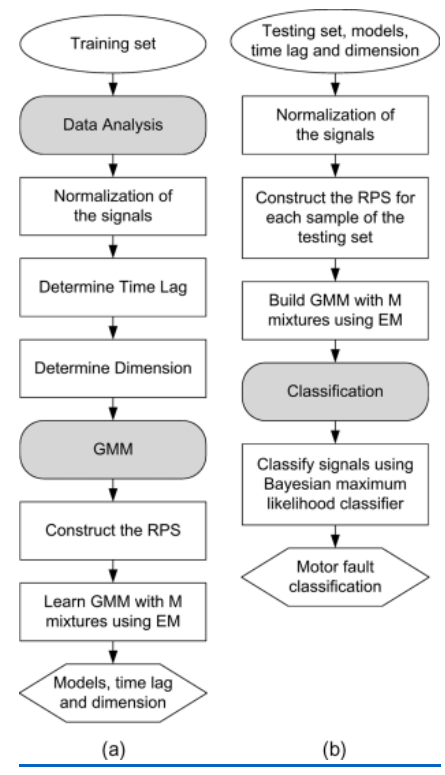

Fig. 2. Algorithm of the presented method. (a) Training stage. (b) Testing or classification stage. 
The training and testing sets are generated from the envelopes of the three-phase stator current of an induction motor for cases involving healthy and faulty operating conditions, such as broken rotor bars and interturn short circuits in the stator windings. The training and testing sets are further discussed in the next sections.

\section{B. Three-Phase Stator Current Envelope}

The objective of this section is to explain the effect of broken rotor bars and interturn short circuits on the three-phase stator currents of IMs. The broken bars produce a phenomenon called envelope that is cyclically repeated at a rate equal to twice the slip frequency $(2 s f)$, and the interturn short circuits cause a profile modification on the three-phase stator current leading to an envelope cyclically repeated at a rate equal to the power frequency $(f)$. The procedure to obtain the three-phase stator current envelope is discussed next.

A healthy rotor has a rotating magnetic field nature that possesses a perfect periodic profile over a two-pole pitch, which leads to a circular trace of the magnetic field's space vector. However, once a rotor develops a single broken bar, the aforementioned periodical profile is lost over the two pole pitches of the rotor containing the broken bar due to the fact that no induced current can flow in the broken bar [5], [19]. Consequently, the magnetic field's neutral plane orientation deviates from the position for the healthy case, which results in an angular shifting in the rotor magnetomotive force waveform. This angular shifting is a function of the number of broken bars and the geometric distribution of the broken bars around the rotor, and varies with time in a cyclical manner, as explained in [5] and [19]. The distortion of the rotor's magnetic field orientation and the resulting local saturation in the rotor laminations around the region of the broken bars lead to a quasi-elliptical trace of the magnetic field's space vector and consequently modulate in a sequential manner the three-phase stator current. The modulation of the three-phase stator current is the so-called envelope. In this paper, this envelope is the feature used for induction motor fault diagnosis. The envelope resulting from the modulation of the threephase stator current for a period equivalent to one slip cycle for a faulty 5-hp IM with four broken bars is shown in the experimentally obtained results plotted in Fig. 3. The laboratory test setup used to obtain these data is shown in Fig. 4.

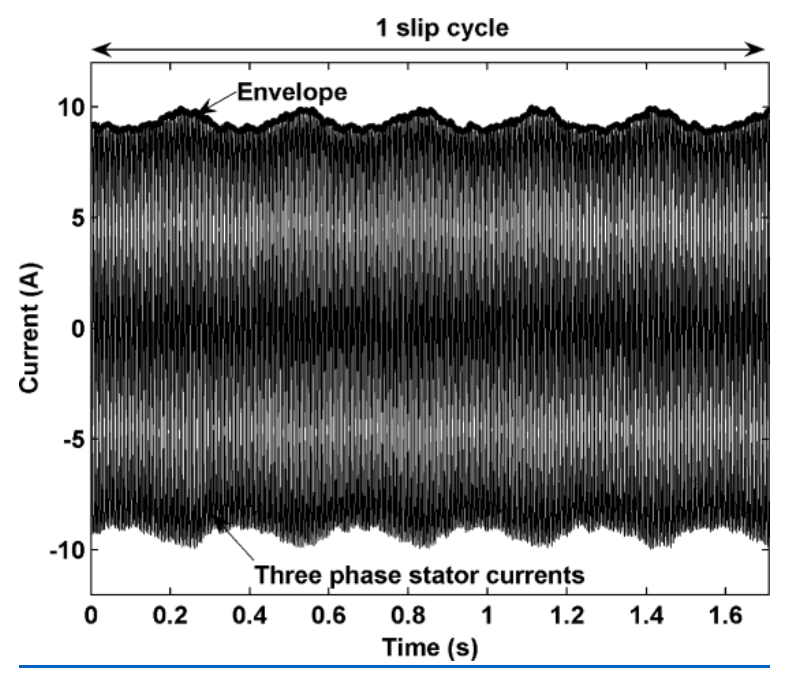

Fig. 3. One slip cycle of the three-phase stator current envelope for a three-phase $460-\mathrm{V} 60-\mathrm{Hz}$ six-pole 5-hp squirrel-cage induction motor with four broken bars under rated load. 


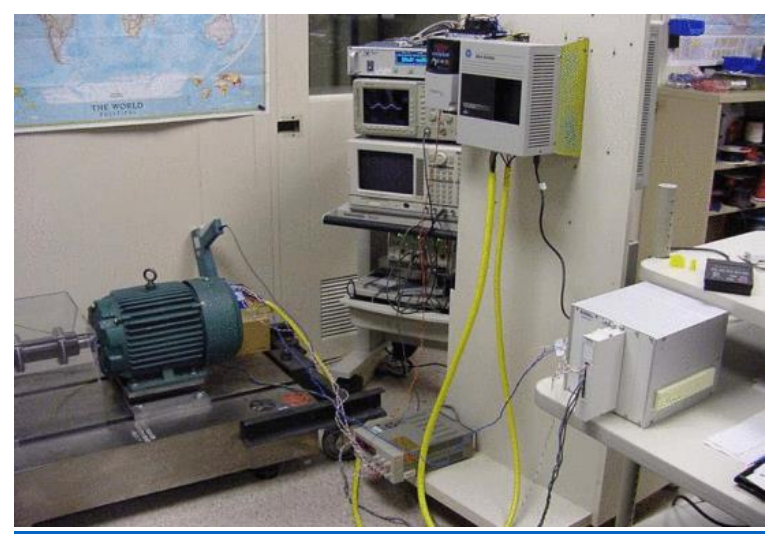

Fig. 4. Laboratory test setup for the 5-hp induction motor and data acquisition.

On the other hand, an interturn short circuit principally affects only the stator current of the faulty phase in both profile and peak value. The other stator phase currents suffer smaller interferences. Thus, the stator current profile of each phase is not equally affected by the fault. This three-phase stator current profile modulation is also referred to here as the so-called envelope. Again, the frequency of repetition of this envelope is the power frequency $f$ and not a function of the slip frequency $s f$, which is associated with broken bar faults. The resulting envelope of the three-phase stator current for the same 5-hp IM with four interturn short circuits without broken bars experimentally obtained under rated load is shown in Fig. 5.

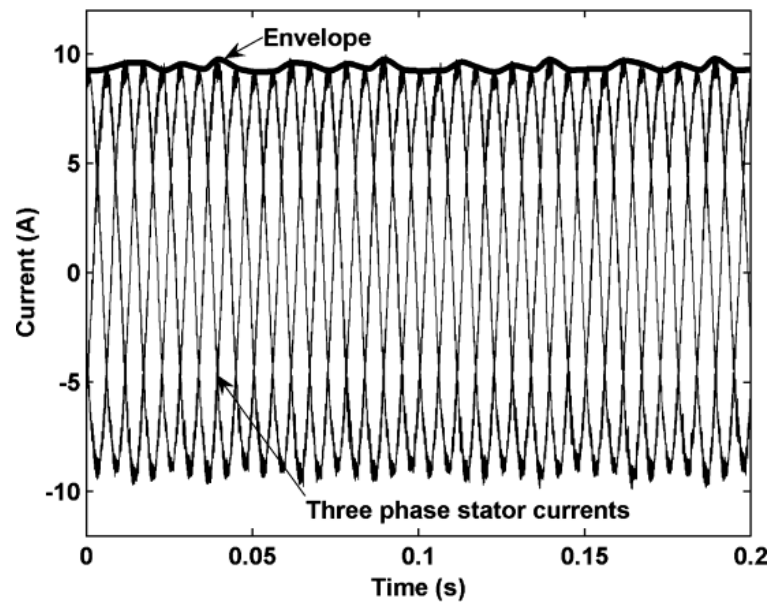

Fig. 5. Three-phase stator current envelope for a three-phase $460-\mathrm{V} 60-\mathrm{Hz}$ six-pole 5 -hp squirrel-cage induction motor with four interturn short circuits under rated load.

The procedures to obtain the three-phase stator current envelopes for the broken bar and interturn short-circuit cases for learning and classification are identical. This procedure can be summarized in the following steps: 1) low-pass filter (LPF); 2) envelope identification; 3) interpolation; and 4) normalization, see the functional block diagram in Fig. 6. The first step is an LPF, which is essential for the IMs supplied by the ac drives. The stator current of an IM supplied by an ac drive has a high-frequency component due to the carrier frequency responsible for the pulse width modulation (PWM) of the ac drive. Typically, the stator current frequency is variable from 0 to $60 \mathrm{~Hz}$, and the carrier frequency is a fixed value in the range from 4 to $16 \mathrm{kHz}$. This PWM component is eliminated from the ac current signal by a sixth-order low-pass elliptic digital filter with a cutoff frequency of $2 \mathrm{kHz}$, a passband of $3 \mathrm{~dB}$, and a stopband of $50 \mathrm{~dB}$ [33]. The cutoff frequency was chosen to be 2 $\mathrm{kHz}$ because the carrier frequency of the ac drive is at least $4 \mathrm{kHz}$. Accordingly, the envelope is isolated from the three-phase stator currents without any significant PWM component. The second step, which is envelope identification, consists of extracting from the three-phase currents only the positive peak of each period in each phase. Thus, in $1 \mathrm{~s}$ of $60 \mathrm{~Hz}$, the three-phase current signal has 180 positive peaks. In the third step, these few 
points are interpolated to smoothly represent the dynamic behavior of the three-phase stator current envelope. The fourth and last step is the z-score normalization that centers the signal at zero mean and scales it to unit standard deviation [34]. After accomplishing these four steps, the identified envelope is used to generate the training set to learn the GMMs or the testing set to classify these unseen input signals with a maximum likelihood Bayes classifier [27]. Again, these steps to isolate the envelope of the three-phase stator currents of a given IM supplied by an ac drive can best be visualized by inspection of Fig. 6 . The procedure that utilizes only three current sensors is easily available and implementable in most industrial applications. In most drives, this current information is readily available, and hence, no extra current sensors are needed to implement this procedure (algorithm).

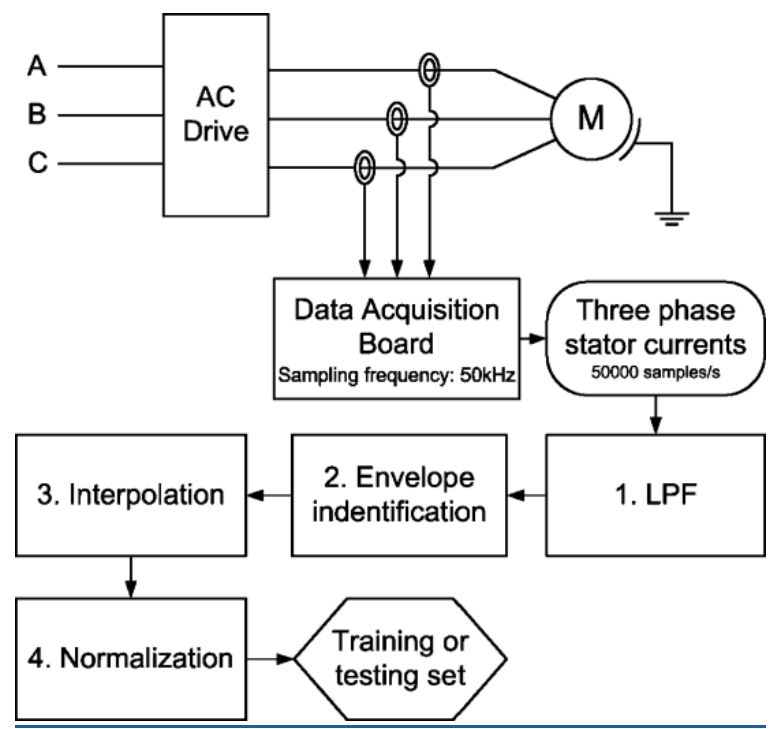

Fig. 6. Procedure to isolate the envelope of the three-phase stator current from an IM supplied by an ac drive for further motor fault classification.

\section{Time Series Data Sets}

A case-study three-phase $460-\mathrm{V} 60-\mathrm{Hz}$ six-pole 5-hp squirrel-cage induction motor supplied by an ac drive operating under scalar (open-loop) constant volts-per-hertz control was tested in the laboratory. This motor has a cage with 45 bars (i.e., $71 / 2$ bars per pole pitch), and it has 240 stator winding turns per phase housed in a stator with 36 slots (i.e., six slots per pole and hence two slots per pole per phase). This motor was tested under healthy and one to four broken bars of rotor faulty conditions, as well as one to four interturn shorts in one phase of the stator windings. Thus, this set of tests yielded nine classes of IM operating conditions. An external resistor $r f$ of $1 \Omega$ was used to emulate a developing or "incipient" interturn short circuit in the stator windings, as depicted in Fig. 7. This resistor also restricts the circulating currents in the shorted portion of the stator winding to a safe level to avoid permanent motor winding damages. In these tests, the loop current in the shorted turn was not allowed to exceed (in root mean square magnitude) three times the rated line current of the motor. 


\section{Stator windings}

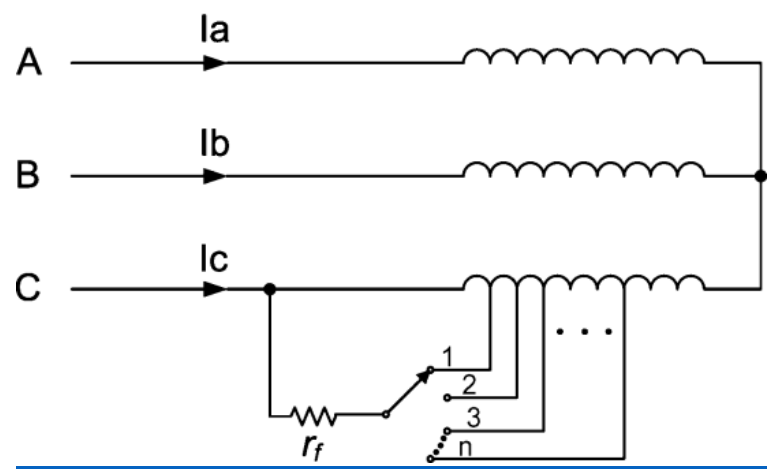

Fig. 7. Schematic of the tapped induction motor windings.

The three-phase stator current was sampled for each class at a $50-\mathrm{kHz}$ sampling frequency using the data acquisition board shown in the functional schematic of Fig. 6 . Each class has $5 \mathrm{~s}$ of signal, which results in 250000 data points each. This $5 \mathrm{~s}$ of signal was equally divided into ten samples, where each sample is a time series. The definition of time series is explained in [26]. Thus, the procedure depicted in Fig. 6 was carried out, and the resulting totality of ten time series of each class yielded the training set as well as the testing set using a cross-validation technique [27], [35]. Cross validation is a well-known technique used when the data set is not large enough to obtain totally independent training and testing sets. The cross validation splits the same data set to generate different training and testing sets. The training and test sets were generated by $K$-fold cross validation with $K=10$ (see [27] and [35]).

The experiment carried out for broken bars has five classes (one to four broken bars and the healthy case), and for the interturn short circuits, it also has five classes (one to four interturn short circuits and the healthy case). However, the last experiment combines all faults plus the healthy case, thus resulting in nine classes.

Accordingly, the number of samples of the testing set generated using $K$-fold cross validation is defined by the number of time series per class times the number of classes. These samples of the testing set are distributed in $K$-folds. Thus, an experiment with five classes $(K=10)$ and ten time series per class has a testing set with 50 samples distributed in ten folds that are to be classified.

\section{SECTION III. Experimental Verification of the Presented Method}

The motor current envelopes obtained from the experimentally acquired motor current data represent two types of motor faults, i.e., broken rotor bars and interturn short circuits in stator windings. The experiment for broken bars was carried out for three different motor loads and for two different ac drive output frequencies, which yields two different motor speeds. On the other hand, the experiment for the interturn short circuits in stator windings was carried out for three values of motor loads at one ac drive output frequency. Finally, the last experiment for broken bars and interturn short circuits yielding nine classes of motor operating conditions was carried out for three levels of motor loads also at one ac drive output frequency. All the experimental results presented below validate the efficacy of this method.

The aforementioned case study of the three-phase 5-hp squirrel-cage induction motor with one to four broken rotor bar faults was tested in the laboratory. The fault classification results for broken bars with the motor running at $60 \mathrm{~Hz}$ and three different levels of loads are shown in Table I. The results for each combination of mixtures of the fault signatures and levels of load torque shown in Table I were generated using a testing set with 50 samples obtained by 10 -fold cross-validation. Here, each sample has a duration of $0.5 \mathrm{~s}$ of the threephase stator current envelopes. Accordingly, the one to four broken rotor bars and the healthy motor case yield five classes of motor operating conditions. Again, the motor was tested with three different magnitudes of load 
that correspond to $50 \%, 75 \%$, and $100 \%$ of the rated torque. It should be pointed out that the rated torque is 30 $\mathrm{N} \cdot \mathrm{m}$. As given in Table I, the accuracy of the resulting fault classification for a motor load of $50 \%$ and $100 \%$ of the rated torque was $100 \%$, i.e., all 50 unseen input samples of the testing set were correctly classified independent of the number of mixtures of the fault signatures. The same level of accuracy was obtained for a motor load of $75 \%$ of the rated torque with 4,16 , and 32 fault signature mixtures. However, a slightly lower fault classification accuracy of $98 \%$ was obtained and is shown in Table I for the $75 \%$ of the rated torque case with eight fault signature mixtures, which means that only one of the 50 samples of the testing set was misclassified.

Additionally, the presented fault classification method not only monitors the faults (thus distinguishing a faulty motor from a healthy motor) but also diagnoses the degree of fault severity (thus identifying the number of broken bars). Here, the degree of fault severity is proportional to the number of broken bars. Furthermore, the presented results were carried out for motor loads over $50 \%$ of the rated torque. However, the accuracy of the fault classification for motor loads below $50 \%$ of the rated torque is slightly lower compared to the accuracies obtained for motor loads above $50 \%$ of the rated torque. Below $50 \%$ of the rated torque, the amplitude and profile of the envelopes for any number of broken bars become very similar to the healthy case in which the amplitude of the envelope is ideally zero. Thus, when signals with similar envelopes are obtained for a given operating condition under healthy and faulty operations, the implication is that there will be difficulties building sets of signatures that efficiently represent the motor fault operating conditions for accurate motor fault classification. In general, this confirms the well-known fact that it is harder to diagnose a fault when a motor is lightly loaded [36]-[37][38]. This is an aspect that is further elucidated in Section IV.

Table I Accuracy of Fault Classification for an Induction Motor With One to Four Broken Bars at $60 \mathrm{~Hz}$ and Three Different Motor Loads Based on a Testing Set With 50 Samples

\begin{tabular}{|l|l|l|l|}
\hline & $\begin{array}{l}\text { Accuracy (\%) } \\
\text { (mean } \pm \text { standard deviation) }\end{array}$ & & \\
\hline Mixtures & Motor load as \% of Rated Torque & & \\
\hline & $\mathbf{5 0 \%}$ & $\mathbf{7 5 \%}$ & $\mathbf{1 0 0 \%}$ \\
\hline $\mathbf{4}$ & $100 \pm 0$ & $100 \pm 0$ & $100 \pm 0$ \\
\hline $\mathbf{8}$ & $100 \pm 0$ & $98 \pm 6$ & $100 \pm 0$ \\
\hline $\mathbf{1 6}$ & $100 \pm 0$ & $100 \pm 0$ & $100 \pm 0$ \\
\hline $\mathbf{3 2}$ & $100 \pm 0$ & $100 \pm 0$ & $100 \pm 0$ \\
\hline
\end{tabular}

Here, Table II presents the accuracy of the broken bar fault classification for the 5-hp motor at rated torque and for two different ac drive output frequencies of 40 and $60 \mathrm{~Hz}$, respectively. The results for $60 \mathrm{~Hz}$ are the same as previously shown in Table I. The testing set for the results at $40 \mathrm{~Hz}$ contains 30 samples instead of 50 samples because the original $5 \mathrm{~s}$ of the current signals for each class is divided into six samples instead of ten samples, which thus yields the three-phase stator current envelope for each sample with a duration of $0.83 \mathrm{~s}$ ( $5 \mathrm{~s} / \mathrm{six}$ time series per class). This higher time sample for the $40-\mathrm{Hz}$ data compared to the $60-\mathrm{Hz}$ data is necessary to have samples with approximately the same number of envelope periods for both cases. This time sample of each input signal that is to be classified can be associated with the operating motor frequency in order to automatically adjust the length of the time sample to be used in the classification. One must bear in mind that both the motor frequency and the length of time sample are inversely proportional to each other. An accuracy of $97 \%$ was obtained and is shown in Table II at $40 \mathrm{~Hz}$ for four and eight fault signature mixtures, which means that this method resulted in only one misclassification out of 30 . Table II includes the results with $90 \%$ classification accuracy for the 16 fault signature mixtures, which means that this method resulted in three misclassifications out of 30 . Meanwhile, an accuracy of $77 \%$ for 32 fault signature mixtures was achieved, which means that this method resulted in seven misclassifications for the testing set with 30 samples. 
Table II Accuracy of Fault Classification for an Induction Motor With One to Four Broken Bars at 40 and $60 \mathrm{~Hz}$ Based on a Testing Set With 30 Samples. The Test was Carried Out at Rated Load

\begin{tabular}{|l|l|l|}
\hline & $\begin{array}{l}\text { Accuracy (\%) } \\
\text { (mean } \pm \text { standard deviation) }\end{array}$ & \\
\hline Mixtures & Motor frequency & \\
\hline & $\mathbf{4 0 ~ H z}$ & $\mathbf{6 0 ~ H z}$ \\
\hline $\mathbf{4}$ & $97 \pm 10$ & $100 \pm 0$ \\
\hline $\mathbf{8}$ & $97 \pm 10$ & $100 \pm 0$ \\
\hline $\mathbf{1 6}$ & $90 \pm 16$ & $100 \pm 0$ \\
\hline $\mathbf{3 2}$ & $77 \pm 16$ & $100 \pm 0$ \\
\hline
\end{tabular}

The interturn short circuit is the second type of motor fault investigated in this paper. This type of fault has five classes, i.e., one to four interturn short circuits and a healthy case. The results of accuracy for the classification of the interturn short circuits in the 5 -hp motor at $60 \mathrm{~Hz}$ and motor loads of 50\%, $75 \%$, and $100 \%$ of the rated torque are shown in Table III. The motor fault classification is highly accurate with a low standard deviation in all the cases shown in this table. These results were based on a testing set with 50 samples. Thus, a $98 \%$ accuracy of classification was achieved, which means that only one misclassification took place. Meanwhile, the case with $96 \%$ classification accuracy represents two misclassifications, and so forth. The different levels of load torque did not result in any loss of accuracy for the classification of interturn short circuits. This lack of effect of load level on the classification results of the shorted turn faults in comparison to the opposite for the cases with broken bars is physically explained in the next section. From Table III, it can be concluded that signatures with 16 mixtures are sufficient to achieve a reasonably high degree of accuracy. However, models with eight mixtures can speed up the learning and classification processes without significant losses in the fault classification accuracy. These fault classification results and associated method constitute a significant contribution for motor fault classification techniques considering that the interturn short circuits represent $30 \%-40 \%$ of the commonly occurring motor faults, with the knowledge that in this method at hand, only the envelopes of the three-phase stator currents are needed.

Table III Accuracy of Fault Classification for an Induction Motor With One to Four Interturn Short Circuits in the Stator Windings at $60 \mathrm{~Hz}$ and Motor Loads of 50\%, 75\%, and 100\% of the Rated Torque Based on a Testing Set With 50 Samples

\begin{tabular}{|l|l|l|l|}
\hline & $\begin{array}{l}\text { Accuracy (\%) } \\
\text { (mean } \pm \text { standard deviation) }\end{array}$ & & \\
\hline Mixtures & Motor load as \% of Rated Torque & & \\
\hline & $\mathbf{5 0 \%}$ & $\mathbf{7 5 \%}$ & $\mathbf{1 0 0 \%}$ \\
\hline $\mathbf{4}$ & $94 \pm 10$ & $94 \pm 10$ & $92 \pm 14$ \\
\hline $\mathbf{8}$ & $98 \pm 6$ & $96 \pm 8$ & $98 \pm 6$ \\
\hline $\mathbf{1 6}$ & $100 \pm 0$ & $96 \pm 8$ & $98 \pm 6$ \\
\hline $\mathbf{3 2}$ & $100 \pm 0$ & $96 \pm 8$ & $98 \pm 6$ \\
\hline
\end{tabular}

The last experiment was carried out for one to four broken bars, one to four interturn short circuits, and the healthy motor case, which yield nine classes of operating conditions. Thus, these nine classes yielded a testing set with 90 samples generated by a 10-fold cross-validation method. The results of the accuracy of classification for the nine different motor operating conditions for the aforementioned 5-hp motor at $60 \mathrm{~Hz}$ and motor loads of $50 \%, 75 \%$, and $100 \%$ of the rated torque are shown in Table IV. The data in this table also show that a more accurate classification result was obtained for fault signatures with 32 mixtures for any level of motor load over 
$50 \%$ of the rated torque, in which case only one of the 90 samples of the testing set was misclassified, which yields a 99\% classification accuracy. These results for 32 fault signature mixtures can be better observed in the so-called "confusion matrix" [35] shown in Table V. The confusion matrix reports the performance of a classifier. It is a square matrix with the dimension defined by the number of classes. The sum of components of each row must contain the same number of samples of the testing set. Each combination of row $i$ and column $j$ contains the number of samples of the testing set classified as the class of the respective column $j$. A confusion matrix that represents a perfect classifier is a diagonal matrix. Additionally, Table $\mathrm{V}$ demonstrates that only one fault was classified as a broken bar fault when it should have been classified as an interturn short circuit. For clarification, it should be pointed out that the headings for the confusion matrix in Table $V$ are defined as follows: $1 \mathrm{~B} \equiv$ one broken bar, $2 \mathrm{~B} \equiv$ two broken bars, $3 \mathrm{~B} \equiv$ three broken bars, $4 \mathrm{~B} \equiv$ four broken bars, $\mathrm{H} \equiv$ healthy, S1 $\equiv$ one turn short circuited, S2 $\equiv$ two turns short circuited, S3 $\equiv$ three turns short circuited, and $\mathrm{S} 4 \equiv$ four turns short circuited. These results demonstrate the relatively high degree of accuracy of fault classification that is associated with the use of the method subject of this paper.

Table IV Accuracy of Fault Classification for an Induction Motor With One to Four Broken Bars or One to Four Interturn Short Circuits in Stator Windings at $60 \mathrm{~Hz}$ and Motor Loads of 50\%, 75\%, and 100\% of the Rated Torque Based on a Testing Set With 90 Samples

\begin{tabular}{|l|l|l|l|}
\hline & $\begin{array}{l}\text { Accuracy (\%) } \\
\text { (mean } \pm \text { standard deviation) }\end{array}$ & & \\
\hline Mixtures & Motor load as \% of Rated Torque & & \\
\hline & $\mathbf{5 0 \%}$ & $\mathbf{7 5 \%}$ & $\mathbf{1 0 0 \%}$ \\
\hline $\mathbf{4}$ & $91 \pm 7$ & $98 \pm 5$ & $98 \pm 5$ \\
\hline $\mathbf{8}$ & $97 \pm 5$ & $98 \pm 5$ & $99 \pm 4$ \\
\hline $\mathbf{1 6}$ & $97 \pm 5$ & $99 \pm 4$ & $99 \pm 4$ \\
\hline $\mathbf{3 2}$ & $99 \pm 4$ & $\mathbf{9 9 \pm 4}$ & $\mathbf{9 9 \pm 4}$ \\
\hline
\end{tabular}

Table V Confusion Matrix for the 99\% Classification Accuracy of the Induction Motor With One to Four Broken Bars or One to Four Interturn Short Circuits in Stator Windings at $60 \mathrm{~Hz}$ and Motor Loads of 50\%, 75\%, and 100\% of the Rated Torque Based on a Testing Set of 90 Samples and With 32 Fault Signature Mixtures

\begin{tabular}{|l|l|l|l|l|l|l|l|l|l|}
\hline & Classified Faults & & & & & & & & \\
\hline Real Faults & 1B & 2B & 3B & 4B & H & S1 & S2 & S3 & S4 \\
\hline 1B & 10 & 0 & 0 & 0 & 0 & 0 & 0 & 0 & 0 \\
\hline 2B & 0 & 10 & 0 & 0 & 0 & 0 & 0 & 0 & 0 \\
\hline 3B & 0 & 0 & 10 & 0 & 0 & 0 & 0 & 0 & 0 \\
\hline 4B & 0 & 0 & 0 & 10 & 0 & 0 & 0 & 0 & 0 \\
\hline H & 0 & 0 & 0 & 0 & 10 & 0 & 0 & 0 & 0 \\
\hline S1 & 1 & 0 & 0 & 0 & 0 & 9 & 0 & 0 & 0 \\
\hline S2 & 0 & 0 & 0 & 0 & 0 & 0 & 10 & 0 & 0 \\
\hline S3 & 0 & 0 & 0 & 0 & 0 & 0 & 0 & 10 & 0 \\
\hline S4 & 0 & 0 & 0 & 0 & 0 & 0 & 0 & 0 & 10 \\
\hline
\end{tabular}

\section{SECTION IV. Discussion of Results}

In this paper, a 5-hp induction motor was investigated for the monitoring and diagnosis of broken rotor bars and interturn short circuits in stator windings with three different magnitudes of motor loads. The three-phase stator current envelope was found here to be a powerful feature of the induction motor for fault classification. 
Each healthy and faulty motor operating condition yielded a signature generated from the three-phase stator current envelope using the GMMs of RPS. The conditional probability of a fault signature for any "unseen signal" was computed for each given signature previously generated during the training stage. Thus, this "unseen signal" was classified using the Bayesian maximum likelihood classifier.

The three-phase stator current envelope for broken bar faults depends on the number and geometric distribution of the broken bars. Two motors with identical ratings and with the same number of broken bars but with different geometrical distributions of the broken rotor bars may yield a misclassification of this fault, because the signatures are learned for a specific number and distribution of broken bars. Different distributions for the same number of broken bars may yield different signatures. Thus, a signature learned for a specific number and distribution of broken bars cannot guarantee a correct classification of the same number of broken bars for different geometrical distributions. This is an open problem not only for the method presented in this paper but also for other techniques that analyze the stator currents [5], [7].

The presented method is exclusively based on the analysis of the three-phase stator current envelopes. The inputs of the presented method are only the training and testing sets composed from experimentally obtained samples of the three-phase stator current envelopes for different motor operating conditions. Thus, there is no need for any other information about the induction motor or its various parameters during the training and testing stages. Moreover, mathematical models of the IMs, ac drives, or any other mathematical formulation or knowledge about the IM are not required. This simplifies the motor fault classification problem because complex calculations related to IMs as well as any specific design information about each individual motor for the purposes of fault diagnostics are not involved. However, the presented method at this point needs signatures built for each different fault at different speeds and torques. This yields many signatures to represent the range of all the possible motor operating conditions. Therefore, the number of signatures may be reduced if the signatures built for a specific operating condition, for example, rated speed and torque, are scaled for any other different operating condition. In this case, the signature generated for the rated conditions must be associated with speed and torque in order to scale it for use in any other motor operating condition. The speed can be directly obtained from either the ac drive, a speed sensor, or a sensorless speed estimator. The torque can be either measured by a torque transducer or calculated through a sensorless torque estimator. Thus, the signatures can be automatically redefined for any value of speed and torque of an IM.

The presented method yielded a high degree of accuracy of motor fault classification even with the IM running at different levels of load torque. This statement is best validated in Table IV, which presents the accuracies of fault classification for nine different healthy and faulty cases of the 5-hp IM. Moreover, Table IV shows the accuracy of motor fault classification for three different levels of load torque and four different numbers of fault signature mixtures. Here, the number of mixtures is manually defined through the analysis of the classification results. From an investigation of Table IV, it can be concluded that the best number of fault signature mixtures is 32 because the accuracy remains high at $99 \%$ for any level of motor load. However, the speed of the training and testing stages of the presented method is directly related to the number of fault signature mixtures. Thus, the presented method can always be speeded up (hastened) in real time by using less fault signature mixtures. From further examination of Table IV, it can be concluded that an accuracy of over $97 \%$ was obtained with the eight fault signature mixtures for any level of motor load over $50 \%$ of the rated load, which is deemed reasonable for general industrial applications. In this case, eight mixtures satisfy the requirement for both a reasonable level of fault classification accuracy and required time of the training and testing processes.

The well-known difficulties normally associated with diagnosing motor faults at light loads [36]-[37][38] were also encountered here. It is observed that the accuracy of this diagnostic method deteriorated for motor loads under $50 \%$ of the rated load values. This is not a new difficulty, and other methods documented in the literature suffer from similar difficulties [36]-[37][38]. This can be physically attributed to the fact that under light load, 
the rotor electric circuit approaches the high-impedance no-load condition, in which the effect of any change in the cage impedance can be masked due to its weak impact at the stator terminals. Furthermore, from a magnetic field point of view, at rated or near rated load, the currents in the bars of a squirrel cage act as a magnetic shield to the bulk of the rotor iron core, and hence that core remains relatively unsaturated or lightly saturated with a good degree of magnetic circular symmetry (no saliency effects). When bar breakages do occur at rated or near rated load conditions, the magnetic shielding effect of the bars is lost at the location of such bar breakage with a resulting higher degree of local magnetic saturation appearing at that spot. Hence, the rotor's circular magnetic symmetry is lost, and an "apparent magnetic saliency or asymmetry" appears in the rotor. This asymmetry rotates at slip speed with respect to the synchronously rotating magnetic field, and this interturn gives rise to the envelope appearing to enclose the three-phase current waveforms. Hence, it is easier to diagnose such a fault using such an envelope under such substantial motor loads. The phenomenon exploited here in this method is muted or weak at light loads and hence arises the difficulty in diagnosis below $50 \%$ of rated load for the 5-hp case study of this paper.

Although a short circuit between turns of two phases and a short circuit in turns of all the phases due to overload or blocked rotor are possible, an interturn short circuit generally first occurs in just one phase. In this case, the stator current envelope of each single phase is not equally modulated. The stator current envelope of the healthy phases is slightly affected by the faulty phase, while the envelope of the faulty phase is highly modulated. Here, an analysis of the stator current envelope of only one phase instead of the three phases cannot be sufficient to correctly diagnose a faulty condition, particularly if this analyzed phase is not the faulty phase. This addresses the reason for the use of a three-phase stator current envelope instead of a single-phase stator current envelope. Independent of the phase in which turns are short circuited, the three-phase stator current envelope associated with the method presented in this paper is sufficient to classify interturn shortcircuit faults. It should be pointed out that difficulties were not encountered in the diagnosis of shorted stator turns at light loads because the fault is exclusively a stator circuit phenomenon, which is detectable independent of the level of load that as mentioned above largely affects the circuit of the rotor.

Additionally, the three-phase stator current envelope constitutes an IM feature that is associated with the method subject of this paper and not only helps monitor a healthy and faulty condition but also diagnoses the number of interturn short circuits in stator windings or the number of broken rotor bars. This diagnostic method yields further important information about the motor operating condition, namely the fault severity. Here, the fault severity is directly related to the number of broken bars or the number of turns involved in an interturn short circuit.

\section{SECTION V. Conclusion and Future Work}

This paper has presented a motor fault diagnosis method for IMs based on three-phase stator current envelopes for broken rotor bars and interturn short circuits in stator windings. Motor fault signatures were generated using GMMs of the RPS transforms. The maximum likelihood of the signature generated for an unseen acquired signal under the previously learned signatures defines the fault class using the Bayesian maximum likelihood classifier.

The high degree of accuracy evidenced through the results suggests that the proposed method can constitute a powerful tool for induction motor fault diagnosis. Moreover, this method not only monitors the IM identifying whether the motor is healthy or faulty but also diagnoses the severity of the fault, i.e., identifying the number of broken bars or the number of turns involved in one interturn short circuit. This characteristic is very import to prevent irreversible motor damages and unexpected shutdown of industrial processes, and to reduce the downtime and cost of production processes. 
Future works will use independent training and testing sets. The training set, in addition to containing actual experimentally obtained results, may be augmented by healthy and faulty motor performance data generated by commercial finite-elements software (Magsoft) based on finite-element methods, while the testing set would be exclusively acquired from an experimental setup or field-acquired data. This would allow the enlargement of the nature of classes of faults to be analyzed and diagnosed.

\section{ACKNOWLEDGMENT}

The authors would like to thank Dr. P. Schmidt and Dr. F. Discenzo of Rockwell Automation for providing the 5$\mathrm{hp}$ test motors and providing access to their laboratory facilities.

\section{REFERENCES}

1.D. Leggate, J. Pankau, D. Schlegel, R. Kerkman and G. Skibinski, "Reflected waves and their associated current", Conf. Rec. 33rd IAS Annu. Meeting, pp. 789-798, 1998.

2.S. Nandi and H. A. Toliyat, "Condition monitoring and fault diagnosis of electrical machines-A review", Conf. Rec. 34th IAS Annu. Meeting, pp. 197-204, 1999.

3.J. Penman, H. G. Sedding, B. A. Lloyd and W. T. Fink, "Detection and location of interturn short circuits in the stator windings of operating motors", IEEE Trans. Energy Convers., vol. 9, no. 4, pp. 652-658, Dec. 1994.

4.C. J. Dister and R. Schiferl, "Using temperature voltage and/or speed measurements to improve trending of induction motor RMS currents in process control and diagnostics", Conf. Rec. 33rd IAS Annu. Meeting, pp. 312-318, 1998.

5.B. Mirafzal and N. A. O. Demerdash, "Induction machine broken-bar fault diagnosis using the rotor magnetic field space-vector orientation", IEEE Trans. Ind. Appl., vol. 40, no. 2, pp. 534-542, Mar./Apr. 2004.

6.M. E. H. Benbouzid, "Bibliography on induction motors faults detection and diagnosis", IEEE Trans. Energy Convers., vol. 14, no. 4, pp. 1065-1074, Dec. 1999.

7.M. E. H. Benbouzid, "A review of induction motors signature analysis as a medium for faults detection", IEEE Trans. Ind. Electron., vol. 47, no. 5, pp. 984-993, Oct. 2000.

8.G. B. Kliman, R. A. Koegl, J. Stein, R. D. Endicott and M. W. Madden, "Noninvasive detection of broken rotor bars in operating induction motors", IEEE Trans. Energy Convers., vol. 3, no. 4, pp. 873-879, Dec. 1988.

9.D. G. Dorrell, W. T. Thomson and S. Roach, "Analysis of airgap flux current and vibration signals as a function of the combination of static and dynamic airgap eccentricity in 3-phase induction motors", IEEE Trans. Ind. Appl., vol. 33, no. 1, pp. 24-34, Jan./Feb. 1997.

10.S. Fruchtenicht, E. Pittius and H. O. Seinsch, "A diagnostic system for three-phase asynchronous machines", Proc. 4th Int. Conf. Elect. Mach. Drives, pp. 163-171, 1989.

11.A. Siddique, G. S. Yadava and B. Singh, "A review of stator fault monitoring techniques of induction motors", IEEE Trans. Energy Convers., vol. 20, no. 1, pp. 106-114, Mar. 2005.

12.F. Zidani, M. E. H. Benbouzid, D. Diallo and M. S. Nait-Said, "Induction motor stator faults diagnosis by a current Concordia pattern-based fuzzy decision system", IEEE Trans. Energy Convers., vol. 18, no. 4, pp. 469-475, Dec. 2003.

13.M. E. H. Benbouzid and H. Nejjari, "A simple fuzzy logic approach for induction motors stator condition monitoring", Proc. IEEE Int. Elect. Mach. Drives Conf., pp. 634-639, 2001.

14.I. Lasurt, A. F. Stronach and J. Penman, "A fuzzy logic approach to the interpretation of higher order spectra applied to fault diagnosis in electrical machines", Proc. 19th Int. Conf. North Amer. Fuzzy Inf. Process. Soc., pp. 158-162, 2000.

15.L. Cristaldi, M. Lazzaroni, A. Monti, F. Ponci and F. E. Zocchi, "A genetic algorithm for fault identification in electrical drives: A comparison with neuro-fuzzy computation", Proc. 21st IEEE IMTC, pp. 1454-1459, 2004. 
16.F. Filippetti, G. Franceschini and C. Tassoni, "Neural networks aided on-line diagnostics of induction motor rotor faults", Conf. Rec. IAS Annu. Meeting, pp. 316-323, 1993.

17.M. Chow and S. O. Yee, "Methodology for on-line incipient fault detection in single-phase squirrel-cage induction motors using artificial neural networks", IEEE Trans. Energy Convers., vol. 6, no. 3, pp. 536-545, Sep. 1991.

18.M. Haji and H. A. Toliyat, "Pattern recognition-A technique for induction machines rotor broken bar detection", IEEE Trans. Energy Convers., vol. 16, no. 4, pp. 312-317, Dec. 2001.

19.B. Mirafzal and N. A. O. Demerdash, "Effects of load magnitude on diagnosing broken bar faults in induction motors using the pendulous oscillation of the rotor magnetic field orientation", IEEE Trans. Ind. Appl., vol. 41, no. 3, pp. 771-783, Jun. 2005.

20.B. Ayhan, M.-Y. Chow and M.-H. Song, "Multiple discriminant analysis and neural-network-based monolith and partition fault-detection schemes for broken rotor bar in induction motors", IEEE Trans. Ind. Electron., vol. 53, no. 4, pp. 1298-1308, Jun. 2006.

21.M. S. Ballal, Z. J. Khan, H. M. Suryawanshi and R. L. Sonolikar, "Adaptive neural fuzzy inference system for the detection of inter-turn insulation and bearing wear faults in induction motor", IEEE Trans. Ind. Electron., vol. 54, no. 1, pp. 250-258, Feb. 2007.

22.J.-H. Jung, J.-J. Lee and B.-H. Kwon, "Online diagnosis of induction motors using MCSA", IEEE Trans. Ind. Electron., vol. 53, no. 6, pp. 1842-1852, Dec. 2006.

23.H. Su and K. T. Chong, "Induction machine condition monitoring using neural network modeling", IEEE Trans. Ind. Electron., vol. 54, no. 1, pp. 241-249, Feb. 2007.

24.W. W. Tan and H. Huo, "A generic neurofuzzy model-based approach for detecting faults in induction motors", IEEE Trans. Ind. Electron., vol. 52, no. 5, pp. 1420-1427, Oct. 2005.

25.A. Bellini, F. Filippetti, G. Franceschini, C. Tassoni and G. B. Kliman, "Quantitative evaluation of induction motor broken bars by means of electrical signature analysis", IEEE Trans. Ind. Appl., vol. 37, no. 5, pp. 1248-1255, Sep./Oct. 2001.

26.R. J. Povinelli, M. T. Johnson, A. C. Lindgren and J. Ye, "Time series classification using Gaussian mixture models of reconstructed phase spaces", IEEE Trans. Knowl. Data Eng., vol. 16, no. 6, pp. 779-783, Jun. 2004.

27.T. M. Mitchell, Machine Learning, New York:McGraw-Hill, 1997.

28.H. D. I. Abarbanel, Analysis of Observed Chaotic Data, New York:Springer-Verlag, 1996.

29.H. Kantz and T. Schreiber, Nonlinear Time Series Analysis, U.K., Cambridge:Cambrige Univ. Press, 2004.

30.T. Sauer, J. A. Yorke and M. Casdagli, "Embedology", J. Stat. Phys., vol. 65, no. 3/4, pp. 579-616, Nov. 1991.

31.F. Takens, "Detecting strange attractors in turbulence", Proc. Dynamical Syst. Turbulence, pp. 366-381, 1980.

32.T. K. Moon, "The expectation-maximization algorithm", IEEE Signal Process. Mag., vol. 13, no. 6, pp. 47-60, Nov. 1996.

33.A. V. Oppenheim and R. W. Schafer, Discrete-Time Signal Processing, NJ, Englewood Cliffs:Prentice-Hall, 1999.

34.R. O. Duda, P. E. Hart and D. G. Stork, Pattern Classification, New York:Wiley-Interscience, 2000.

35.S. M. Weiss and C. A. Kulikowski, Computer Systems That Learn: Classification and Prediction Methods from Statistics Neural Nets Machine Learning and Expert Systems, CA, San Mateo:Morgan Kaufmann, 1991.

36.W. T. Thomson and M. Fenger, "Industrial application of current signature analysis to diagnose faults in 3phase squirrel cage induction motors", Proc. Conf. Rec. Annu. Pulp Paper Ind. Tech. Conf., pp. 205-211, 2000.

37.A. M. Trzynadlowski and E. Ritchie, "Comparative investigation of diagnostic media for induction motors: A case of rotor cage faults", IEEE Trans. Ind. Electron., vol. 47, no. 5, pp. 1092-1099, Oct. 2000.

38.S. M. A. Cruz and A. J. M. Cardoso, "Rotor cage fault diagnosis in three-phase induction motors by the total instantaneous power spectral analysis", Conf. Rec. 34th IAS Annu. Meeting, pp. 1929-1934, 1999. 